\title{
Exergy Analysis of the Revolving Vane Compressed Air Engine
}

\author{
Alison Subiantoro, ${ }^{1,2}$ Kin Keong Wong, ${ }^{3}$ and Kim Tiow Ooi ${ }^{2,3}$ \\ ${ }^{1}$ Department of Industrial and Systems Engineering, Krida Wacana Christian University, Jalan Tanjung Duren Raya No. 4, \\ Jakarta Barat 11470, Indonesia \\ ${ }^{2}$ Technical University of Munich-Campus for Research Excellence and Technological Enterprise (TUM CREATE), \\ 1 CREATE Way No. 10-02, CREATE Tower, Singapore 138602 \\ ${ }^{3}$ School of Mechanical and Aerospace Engineering, Nanyang Technological University, 50 Nanyang Avenue, Singapore 639798 \\ Correspondence should be addressed to Alison Subiantoro; alison.subiantoro@ukrida.ac.id
}

Received 3 December 2015; Revised 14 January 2016; Accepted 14 January 2016

Academic Editor: Zuohua Huang

Copyright (C) 2016 Alison Subiantoro et al. This is an open access article distributed under the Creative Commons Attribution License, which permits unrestricted use, distribution, and reproduction in any medium, provided the original work is properly cited.

Exergy analysis was applied to a revolving vane compressed air engine. The engine had a swept volume of $30 \mathrm{~cm}^{3}$. At the benchmark conditions, the suction pressure was $8 \mathrm{bar}$, the discharge pressure was $1 \mathrm{bar}$, and the operating speed was $3,000 \mathrm{rev} \cdot \mathrm{min}^{-1}$. It was found that the engine had a second-law efficiency of $29.6 \%$ at the benchmark conditions. The contributors of exergy loss were friction (49\%), throttling (38\%), heat transfer (12\%), and fluid mixing (1\%). A parametric study was also conducted. The parameters to be examined were suction reservoir pressure ( 4 to $12 \mathrm{bar}$ ), operating speed (2,400 to 3,600 rev $\cdot \mathrm{min}^{-1}$ ), and rotational cylinder inertia $\left(0.94\right.$ to $\left.2.81 \mathrm{~g} \cdot \mathrm{mm}^{2}\right)$. The study found that a higher suction reservoir pressure initially increased the second-law efficiency but then plateaued at about $30 \%$. With a higher operating speed and a higher cylinder inertia, second-law efficiency decreased. As compared to suction pressure and operating speed, cylinder inertia is the most practical and significant to be modified.

\section{Introduction}

Since its inception in the 1800 s, reciprocating piston engines have been widely used to drive motor vehicles. However, even with all the progress and innovations in the reciprocating engine technology, there are still issues and challenges facing the engine design. To overcome these, there have been attempts to come up with new engine designs. Rotary engines have been proposed as a possible design alternative. As compared to a reciprocating engine, rotary engines are usually more compact and have less number of components with better vibration and noise characteristics. In response, Wankel developed a rotary piston engine in the 1960s which has been adopted by Mazda to drive its sport vehicles. However, leakage is one of the main issues with this engine design [1]. More recently, Sakita introduced a new rotary machine design called the "cat and mouse type" rotary engine [2]. Shen and Hwang adopted the sliding vane machine design for an air-powered motorcycle [3].

In 2006, a new rotary machine design concept called the revolving vane (RV) mechanism was introduced by Teh and Ooi [4]. An improved version was later proposed to improve the mechanical efficiency of the machine [5]. Unlike the more common rotary machines which use stationary cylinders, the RV machine lets the cylinder move together with the rotor. This significantly reduces the frictions of the machine. In addition, it is also found that the RV machine exhibits better volumetric performance as compared to a rolling piston machine [6]. The machine was first introduced as a compressor but has subsequently been used in expander and air engine applications too [7-9].

In its simplest form, the RV mechanism consists of a rotor, a vane, and a cylinder as shown in Figure 1(a). However, unlike other rotary machines, the cylinder rotates together with the rotor, resulting in smaller relative velocities and less frictional losses at the rubbing surfaces. The rotor and the cylinder are arranged eccentrically and they rotate at their respective axes. The vane divides the space between the rotor and the cylinder inner wall into two, that is, the suction and discharge chambers. As the rotor rotates, the volumes of these chambers vary allowing for thermodynamics processes to 


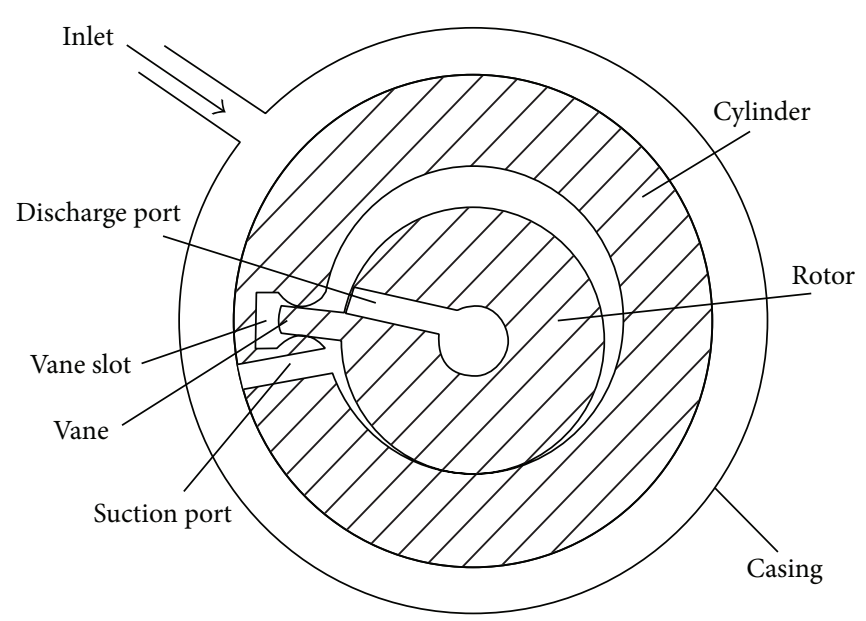

(a)

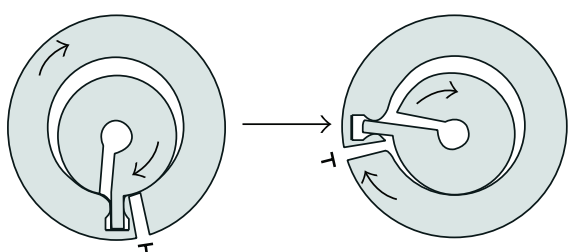

(A)

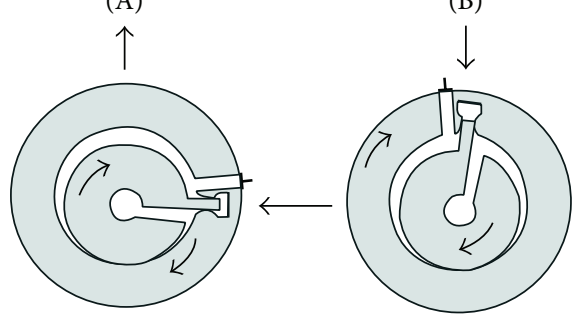

(D)
(C)

(b)

FIGURE 1: Revolving vane engine: (a) schematics and (b) working principles [6].

occur. A stationary casing is usually required to house the engine. The working principles of an RV engine are shown in Figure 1(b).

Meanwhile, it was reported that through the burning of fossil fuels, mainly gasoline and diesel, the transportation sector contributed around $15 \%$ of the total global greenhouse emission [10]. Therefore, various cleaner alternative fuels have been proposed in the recent years. Among others, one of the most interesting is the compressed air engine $[3,11,12]$. In this paper, the RV machine is adopted for air engine application. Various aspects of the mechanism have been comprehensively studied before $[7-9,13]$. However, an exergy analysis of the machine is still lacking. It is the purpose of this paper to describe the exergy analysis of the RV compressed air engine to quantify the irreversibilities involved in the operation. This analysis will help to improve the future design process of the machine.

Exergy, also known as availability, is the maximum amount of useful work that can be derived from a substance in bringing it to an equilibrium state with the environment. The exergy of a system is the maximum useful work possible in a process that brings the system into thermal equilibrium with its surroundings. After the system and surroundings reach equilibrium, the exergy is zero. Exergy also accounts for the irreversibility of a process.

In addition to the first law, exergy analysis also uses the second law of thermodynamics, which deals with the concepts of quality of energy as well as entropy of a system. As exergy is a property of the system, the exergies of the fluid before and after the cycle can be quantified. The loss will then be the reduction in total exergy of the system. The secondlaw efficiency is determined as well and it provides a more comprehensive evaluation of the efficiency of the engine.

Exergy analysis has been carried out for various machines, including compressors and engines. McGovern et al. [14] developed an analysis technique that uses the exergy of a gas to quantify the shaft power wastage in scroll and rotary compressors. They summarized the losses in a compressor to be mainly contributed by throttling at valves, mechanical friction, leakage, heat transfers, and reexpansion of compressed gases. By employing equations of irreversibilities for the different components, they were able to quantify that the major losses in the compressor are due to throttling (12\%), leakage (40\%), and friction (24\%). In another paper, McGovern and Harte [15] performed an exergy analysis for an open reciprocating compressor. They showed that results from computer simulations of compressors can be readily utilised to provide an understanding for design optimization. The breakdown of shaft power wastage could be quantified using simulations and instantaneous exergy destruction rates of the different components are presented. Overall, it was found that the major contributions are due to throttling (53.7\%), internal convection (18.7\%), friction (12.5\%), and fluid mixing (5.7\%). The exergy analysis in this paper used the method used in the study.

In other papers, McGovern [16, 17] outlined the methods of exergy analysis and reported that it is common for compressors to have second-law efficiencies of about $50 \%$. Stecco and Manfrida [18] and McGovern [19] have proposed the case for using exergy analysis to measure efficiency of compressors. Both concluded that exergy analysis could be applied to all types of compressors and could be applied to study of an entire plant or cycle.

Reddy et al. [20] performed an exergy analysis on internal combustion engines using either diesel or biogas-diesel mixture as fuel. Similar works on internal combustion engines have also been carried out by other researchers [21-24].

\section{Methodology}

Mathematical models of various aspects of an RV engine have been presented in detail and experimentally verified before $[7-9,25]$. Therefore, they will not be discussed again 
here. Interested readers are directed to the relevant literature. Developing on the foundation of those models, the exergy model of RV engine was created.

In an RV engine, exergy is destroyed mostly through heat transfer between the working fluid, the solid components and the surrounding, dissipated heat from friction between the rubbing surfaces, fluid throttling, and fluid mixing. During operation, the working fluid undergoes thermodynamics processes and its temperature varies. This results in heat transfers between the fluid, the engine components, and the surrounding. This heat energy can potentially be used to produce work. However, in reality, some energy will be wasted resulting in exergy destruction. Simultaneously, some of the engine's moving components rub against one another during operation. This increases the local temperature that is eventually dissipated as heat, resulting in exergy destruction. There are fluid flows into, within, and out from the engine too. As a fluid enters a control volume, its pressure drops because downstream pressure is lower than the upstream. This drop is called throttling and it destroys exergy. Moreover, if the temperatures between upstream and downstream are different, there will be additional exergy destruction due to the fluid mixing.

Exergy destruction rates due to heat transfer, friction, throttling, and mixing can be expressed according to (1) as proposed by McGovern and Harte [15]:

$$
\begin{aligned}
& \dot{I}_{\mathrm{ht}}=\dot{Q}_{j} T_{0}\left(\frac{1}{T}-\frac{1}{T_{j}}\right), \\
& \dot{I}_{f}=\dot{w}_{f}\left(\frac{T_{0}}{T_{j}}\right), \\
& \dot{I}_{\mathrm{th}}=T_{0} \dot{m}\left(s_{i}^{\prime}-s_{i}\right), \\
& \dot{I}_{\mathrm{mx}}=T_{0} \dot{m}\left(\left(s-s_{i}^{\prime}\right)-\frac{\left(h_{i}^{\prime}-h_{i}\right)}{T}\right),
\end{aligned}
$$

where $s_{i}^{\prime}$ is the specific entropy after throttling, computed at the pressure of the bulk fluid in the system and at enthalpy $h_{i}^{\prime}=h_{i}$.

A parameter called the second-law efficiency can be introduced to quantify the exergy performance of the system according to (2). The amount of exergy supplied is computed from the inflow of fluid into the suction chamber according to (3) as proposed before [26]:

$$
\begin{aligned}
& \eta=1-\frac{\dot{I}}{\dot{E}} \\
& \dot{E}=\dot{m}\left[\left(h-h_{0}\right)-T_{0}\left(s-s_{0}\right)\right] .
\end{aligned}
$$

In the exergy analysis of RV engine, two control volumes were in focus, that is, the engine's suction and discharge chambers. In both chambers, exergy was destroyed by friction and heat transfer. In addition, at the suction chamber, there were inflow of fluid from the suction reservoir and outflow due to internal leakage. At the discharge chamber, there were inflow of fluid from suction chamber due to leakage and
TABLE 1: Benchmark operating conditions and major dimensions.

\begin{tabular}{lc}
\hline Item & Value \\
\hline Working fluid & Air \\
Operating speed & $3000 \mathrm{rev} \cdot \mathrm{min}^{-1}$ \\
Suction reservoir temperature & $25^{\circ} \mathrm{C}$ \\
Suction reservoir pressure & $8 \mathrm{bar}$ \\
Discharge reservoir temperature & $25^{\circ} \mathrm{C}$ \\
Discharge reservoir pressure & $1 \mathrm{bar}$ \\
Atmospheric temperature & $25^{\circ} \mathrm{C}$ \\
Radius of rotor & $29 \mathrm{~mm}$ \\
Inner radius of cylinder & $35 \mathrm{~mm}$ \\
Length of engine chamber & $25 \mathrm{~mm}$ \\
Rotating inertia of rotor & $0.21 \mathrm{~g} \cdot \mathrm{m}^{2}$ \\
Rotating inertia of cylinder & $2.81 \mathrm{~g} \cdot \mathrm{m}^{2}$ \\
Friction coefficient of vane & 0.15 \\
Assembly radial clearance & $20 \mu \mathrm{m}$ \\
Vane endface total gap width & $180 \mu \mathrm{m}$ \\
Cylinder endface total gap width & $40 \mu \mathrm{m}$ \\
\hline
\end{tabular}

outflow to the discharge reservoir. These flows contributed to exergy destruction through throttling and mixing.

A simulation code to model the exergy behaviour of an RV engine was developed in MATLAB programming language. This code was coupled to the existing RV engine models mentioned at the beginning of this section. Whenever required, a general convergence criterion of $1 \%$ was used throughout the simulation. The benchmark operating conditions and major dimensions of the RV engine are shown in Table 1 . The design configuration of the RV engine studied is shown in Figure 2. These follow those used in the validation of the RV engine models reported previously [25].

Following the benchmark analysis, a parametric study was conducted to analyse how different parameters affect the exergy behaviours. The parameters to be examined were suction reservoir pressure, operational speed of engine, and rotational cylinder inertia. These parameters were selected because they were found to affect the performance of the engine significantly in previous studies [7]. Moreover, these parameters can be changed independently without affecting the other parameters during the study.

\section{Results and Discussion}

The benchmark results gathered from the simulation are presented and discussed in this section. Following the discussion, a parametric study was presented.

3.1. Benchmark Conditions. Figure 3(a) shows the instantaneous exergy destruction rate due to heat transfer. The heat transfer was between the working fluid and the surrounding walls. The wall temperature was assumed constant and equal to the surrounding temperature. The figure shows that exergy destruction rate due to heat transfer in the suction chamber was significantly higher than that of the discharge chamber throughout the cycle. This is because of the greater 


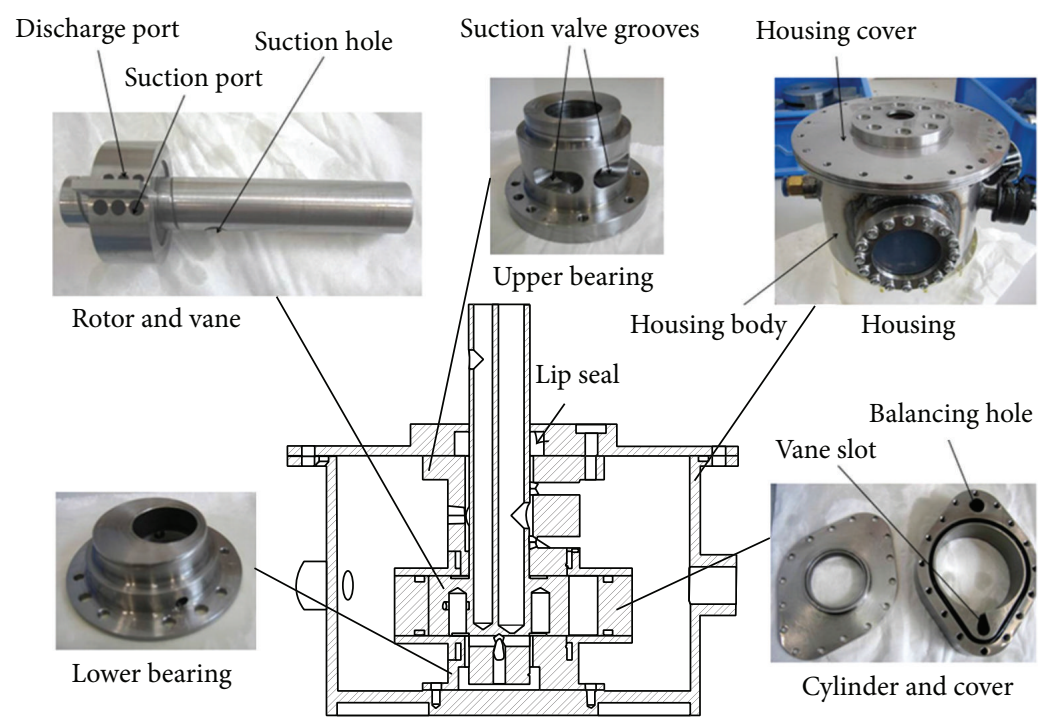

FIGURE 2: The revolving vane engine components and sectional drawing [25].

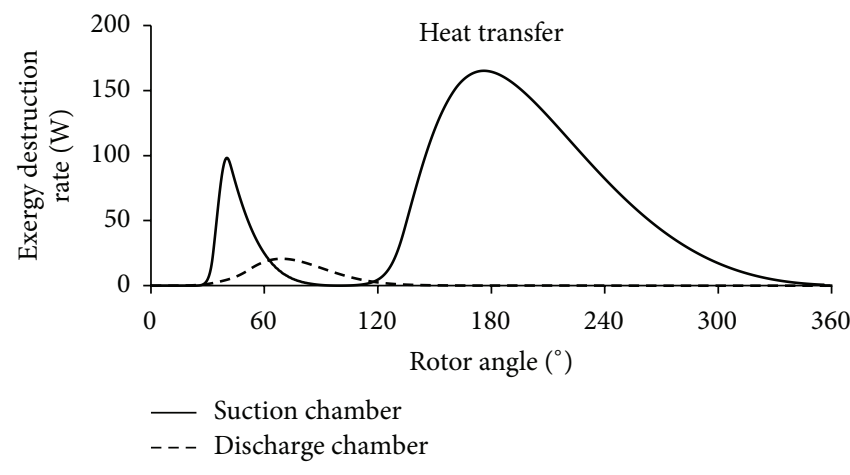

(a)

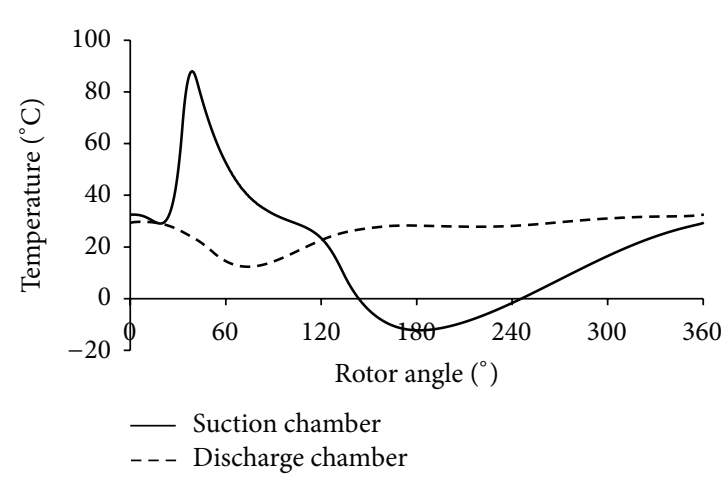

(b)

FIgURE 3: (a) Exergy destruction rate due to heat transfer and (b) temperature variations of the fluid.

temperature fluctuation of the fluid in the suction chamber as compared to that in the discharge chamber as shown by Figure 3(b). In the suction chamber, fluid temperature increased rapidly at the start of the cycle due to the rapid increase in pressure at the beginning of the suction process. Temperature then fell due to heat transfer to the surrounding walls for the rest of the suction process. It subsequently decreased rapidly when the expansion process started. However, when the temperature was too low, it bounced back because of heat transfer from the walls. Temperature of fluid in the discharge control volume was fairly constant. There was a slight variation at the beginning of the cycle due to the rapid drop of pressure in the chamber when it was first exposed to the discharge reservoir.

Figure 4 shows the instantaneous exergy destruction rate due to friction. Exergy destruction due to vane friction was dominant, followed by the cylinder bearing, while the rest were almost negligible. This was due to the high cylinder inertia of the engine prototype used in this study. It is the characteristic of the RV engine that its vane contact force and the corresponding frictional loss are linearly proportional

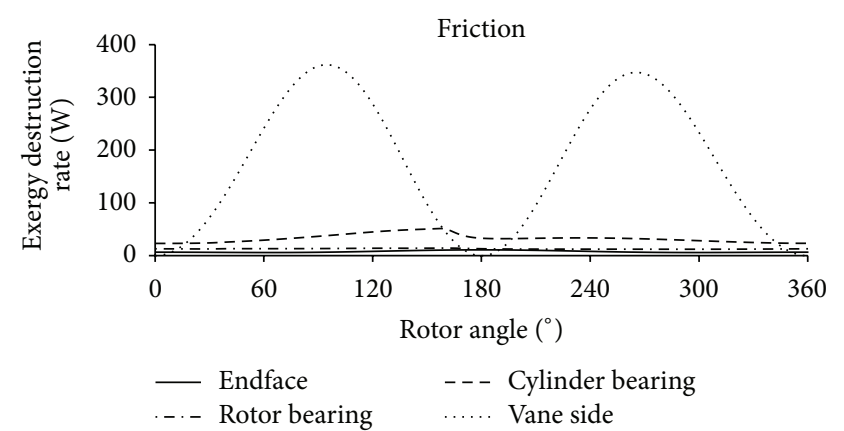

FIgURE 4: Exergy destruction rate due to friction.

to the cylinder inertia. The results suggest that it is crucial to reduce the cylinder inertia to improve the exergy performance of the engine.

Figure 5(a) shows the instantaneous exergy destruction rate due to throttling. Average contributions of inflow, outflow, and leakage were comparable. The highest exergy 


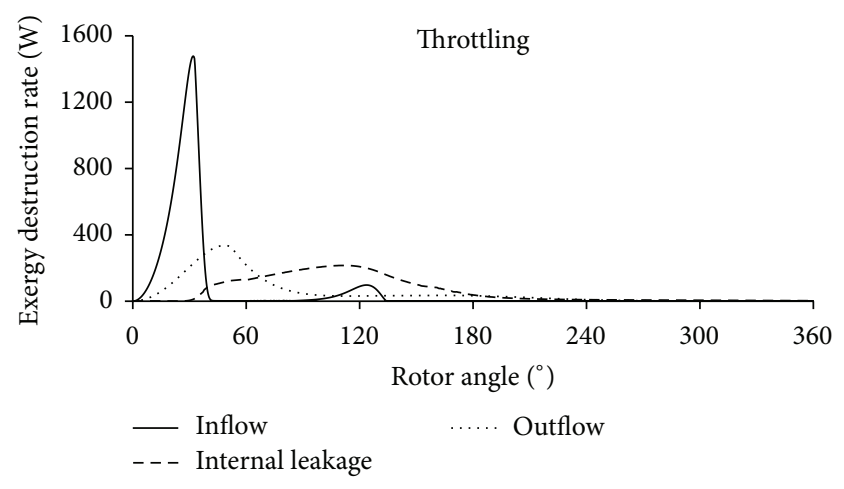

(a)

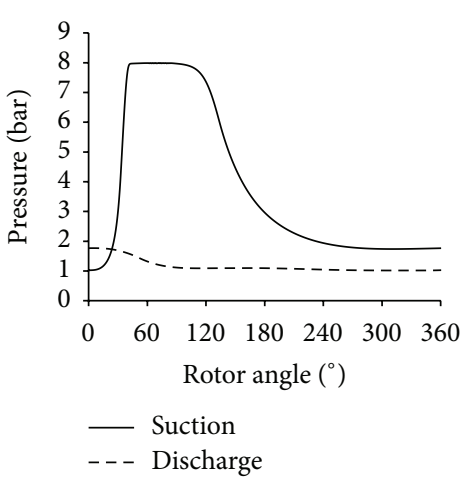

(b)

FIGURE 5: (a) Exergy destruction rate due to throttling and (b) pressure variations of the fluid.

destruction of the inflow into the suction chamber occurred at a rotor angle of around $30^{\circ}$. This was when inflow rate into the suction chamber from the suction reservoir was the highest. It did not occur earlier because of the progressive uncovering of the suction port. For the outflow from the discharge chamber, exergy destruction peaked at a rotor angle of around $45^{\circ}$. This was when the outflow rate was the highest. Like the inflow, it did not occur at an earlier rotor angle due to the progressive opening of the discharge port. However, the uncovering process of the discharge port was slower as compared to the suction port. High exergy destruction rate was observed at rotor angles from $30^{\circ}$ to $180^{\circ}$. This corresponds to the high leakage flow rate from the suction to discharge chambers because of the large pressure difference between the chambers as shown in Figure 5(b). From the findings, it can be inferred that, to reduce exergy destruction due to throttling, the uncovering processes of the ports should be made faster. This can be done by placing the ports closer to the vane and by increasing the diameter of the ports. For the leakage, tightening the leakage gaps to reduce its flow rate will help to reduce the exergy destruction.

Figure 6 shows the exergy destruction rate due to fluid mixing. The exergy destruction due to inflow dominated the rest. This was due to the significantly higher flow rate and fluid properties differences of the inflow as compared to the outflow and leakage. This is particularly true when the pressure in the suction chamber was different from that in the suction reservoir. Once the two pressures equated, the exergy destruction rate dropped rapidly.

Overall, the average exergy supply rate into the engine was $661.6 \mathrm{~W}$ while the average exergy destruction rate was $465.6 \mathrm{~W}$. This equates to second-law efficiency of $29.6 \%$. The breakdown of the overall exergy destruction is shown in Table 2. It can be seen that the main contributor of exergy loss was friction, accounting for almost half of the total loss. Therefore, it can be concluded that the first step to improve the RV engine's performance is to reduce its frictional loss.

3.2. Parametric Study. The effects of different suction reservoir pressure conditions to exergy are shown in Table 3. In order to avoid over- and underexpansions, the suction valve
TABLE 2: Breakdown of average exergy destruction rate of the RV engine.

\begin{tabular}{lcc}
\hline Item & Value $(\mathrm{W})$ & Contribution \\
\hline Heat transfer & 55.3 & $12 \%$ \\
Friction & 226.2 & $49 \%$ \\
Throttling & 179.0 & $38 \%$ \\
Fluid mixing & 5.1 & $1 \%$ \\
\hline
\end{tabular}

TABLE 3: Data of variation of suction reservoir pressure.

\begin{tabular}{lccccc}
\hline Suction pressure (bar) & 4 & 6 & 8 & 10 & 12 \\
\hline Suction valve opening angle & $116^{\circ}$ & $94^{\circ}$ & $84^{\circ}$ & $67^{\circ}$ & $58^{\circ}$ \\
Second-law efficiency & $3.0 \%$ & $30.0 \%$ & $29.6 \%$ & $31.6 \%$ & $30.2 \%$ \\
Exergy supplied (W) & 359 & 551 & 662 & 737 & 803 \\
Exergy destroyed (W) & 348 & 386 & 466 & 504 & 560 \\
Contribution of throttling (W) & 100 & 119 & 179 & 206 & 249 \\
Contribution of friction (W) & 224 & 225 & 226 & 226 & 227 \\
\hline
\end{tabular}

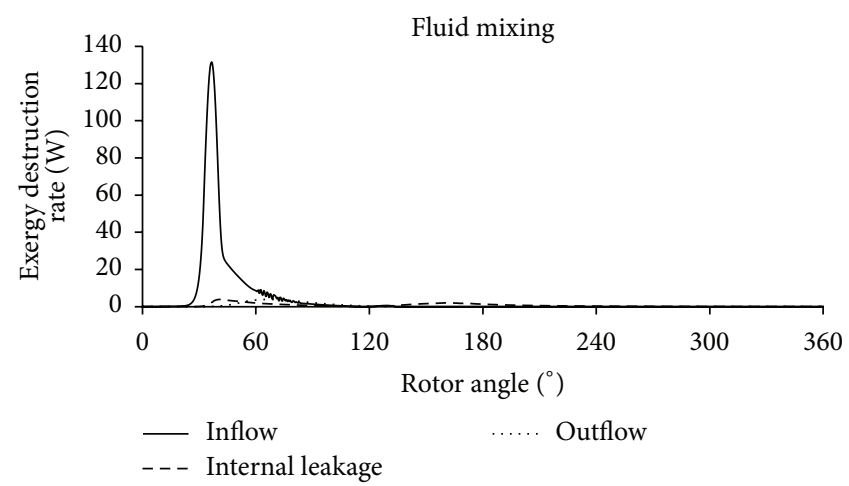

FIGURE 6: Exergy destruction rate due to fluid mixing.

opening angle was varied accordingly. The results show that a higher suction reservoir pressure resulted in higher exergy destruction of the engine. This is due to throttling, and not friction, as can be seen in the table. Friction is not a factor here because pressure does not affect the frictional loss of an RV engine significantly, which is one of the unique characteristics 
TABLE 4: Data of variation of operating speed.

\begin{tabular}{lccc}
\hline Operating speed $\left(\mathrm{rev} \cdot \mathrm{min}^{-1}\right)$ & 2,400 & 3,000 & 3,600 \\
\hline Second-law efficiency & $38.6 \%$ & $29.6 \%$ & $22.1 \%$ \\
Exergy destroyed (W) & 321 & 466 & 654 \\
Exergy supplied (W) & 523 & 662 & 839 \\
Contribution of throttling (W) & 149 & 175 & 179 \\
Contribution of friction (W) & 123 & 226 & 374 \\
\hline
\end{tabular}

of the mechanism. At the same time, a higher suction pressure resulted in higher exergy supplied, as the fluid had a higher potential to do useful work. The exergy supply is increased by the increase in suction mass flow rate too. The total effect was quantified by the second-order efficiency. It is observed that second-law efficiency climbed rapidly as suction pressure increases from 4 to 6 bar, but it stayed almost constant at around $30 \%$ from 6 to 12 bar. At 4 bar, the exergy supply rate was too low. As suction pressure was increased, both the exergy supply and destruction rates increased at the same pace. Hence, the second-law efficiency plateaus beyond suction pressure of 6 bar.

From this analysis, the engine prototype was found to be not suitable for operation at suction pressures below 6 bar. This is a specific behaviour of this particular engine, not a general conclusion, as the prototype was designed for such applications. When the engine is needed for a low suction pressure application, some of the design parameters, such as engine dimensions and bearing sizes, should be modified to reduce the corresponding frictional losses.

The effects of different operational speed to exergy behaviour of an RV engine are shown in Table 4. Generally, exergy destruction rate increased as rotational speed increased. The main losses came from higher fluid throttling losses and frictional losses. The higher throttling loss was because of the inability of the suction to catch up with the increasing speed. The higher frictional loss was because of the higher rotational acceleration, which increased the contact force and the corresponding frictional force at the vane contact line with the cylinder.

At the same time, a higher rotational speed also increased the mass flow rate, resulting in a higher exergy supply rate. However, the exergy destruction rate increased faster over the same range. Hence, the second-law efficiency decreased as speed increased. A low operating speed is hence favourable to maximise the work potential of the high-pressure fluid. However, a low operating speed will limit the output power of the engine. Therefore, a compromise has to be made between the output power and the second-law efficiency in practice.

The effects of different cylinder inertias to the exergy characteristics of RV engine are tabulated in Table 5. It can be seen that exergy destruction increased as the cylinder inertia increased. This is mainly because lower cylinder inertia gave a lower vane frictional loss. Interestingly, throttling loss was smaller with a smaller inertia, although not so significantly. This was because of the increased internal leakage due to larger radial clearance gap with a lighter cylinder. The bearings must be redesigned if a light cylinder was to be used
TABLE 5: Data of variation of cylinder inertia.

\begin{tabular}{lccc}
\hline Cylinder inertia $\left(\mathrm{g} \cdot \mathrm{m}^{2}\right)$ & 0.94 & 1.87 & 2.81 \\
\hline Second-law efficiency & $49.9 \%$ & $39.2 \%$ & $29.6 \%$ \\
Exergy destroyed (W) & 332 & 403 & 466 \\
Exergy supplied (W) & 662 & 662 & 662 \\
Contribution of throttling (W) & 163 & 175 & 179 \\
Contribution of friction (W) & 109 & 167 & 226 \\
\hline
\end{tabular}

to keep this clearance gap small. Meanwhile, exergy supplied by the fluid was maintained at a constant rate in this case as the suction reservoir pressure and rotational speed were kept the same. Therefore, the second-law efficiency was the highest when cylinder inertia is the smallest. It can be seen that the effect of inertia to second-law efficiency is significant. As compared to suction pressure and operating speed, cylinder inertia is the most practical to be modified as the others are based on operating demands. A smaller inertia can be achieved by removing the unnecessary mass of the cylinder (without compromising its dynamic balance) or by using a lower density material (without compromising its strength).

\section{Conclusion}

Exergy analysis has been applied to the revolving vane compressed air engine. The air engine had a rotor radius of $29 \mathrm{~mm}$, cylinder radius of $35 \mathrm{~mm}$, and length of $25 \mathrm{~mm}$. At the benchmark conditions, the suction pressure was 8 bar, the discharge pressure was 1 bar, and the operating speed was $3,000 \mathrm{rev} \cdot \mathrm{min}^{-1}$. Temperatures of suction reservoir, discharge reservoir, and atmosphere were $25^{\circ} \mathrm{C}$. Four main sources of exergy destruction were identified, namely, heat transfer, friction, throttling, and fluid mixing. From the analysis, the following was found:

(i) Overall, the air engine had a second-law efficiency of $29.6 \%$. The main contributor of exergy loss was friction (49\%), followed by throttling (38\%) and heat transfer (12\%). The exergy loss due to fluid mixing is almost negligible.

(ii) The main contributor of the exergy destruction rate due to heat transfer is in the suction chamber due to the large temperature fluctuation of the fluid in it.

(iii) The main contributor of exergy destruction due to friction was that at the vane, followed by the cylinder bearing, while the rest were almost negligible. This was due to the high cylinder inertia of the engine prototype used. The results suggest that it is crucial to reduce the cylinder inertia to improve the performance of the engine.

(iv) The contributions of inflow, outflow, and internal leakage to the average exergy destruction due to throttling were comparable. From the findings, it was found that, to reduce exergy destruction due to throttling, the uncovering processes of the ports 
should be made faster. This can be done by placing the ports closer to the vane and by increasing the diameter of the ports. For the leakage, tightening the leakage gaps to reduce its flow rate will help to reduce the exergy destruction.

(v) The exergy destruction due to mixing was dominated by the inflow. However, the overall contribution of fluid mixing to the exergy loss is very small (around $1 \%)$.

A parametric study was also conducted to analyse how different parameters affect the exergy behaviours. The parameters to be examined were suction reservoir pressure (from 4 to 12 bar), operational speed of engine (from 2,400 to $3,600 \mathrm{rev} \cdot \mathrm{min}^{-1}$ ), and rotational cylinder inertia (from 0.94 to $2.81 \mathrm{~g} \cdot \mathrm{mm}^{2}$ ). The study found the following:

(i) A higher suction reservoir pressure resulted in both higher exergy destruction and supply of the engine. However, the rates of change were different so the second-law efficiency climbed rapidly as suction pressure increases from 4 to 6 bar, but it stayed almost constant at about 30\% from 6 to 12 bar. From this analysis, the engine prototype was found to be not suitable for operation at suction pressures below 6 bar. When the engine is needed for a low suction pressure application should be modified.

(ii) Both exergy destruction and supply rates increased as the rotational speed increased. However, the exergy destruction rate increased faster. Hence, the secondlaw efficiency decreased as speed increased. A low operating speed is therefore favourable to maximise the work potential of the high-pressure fluid. However, it is noted that a low operating speed will limit the output power of the engine.

(iii) Exergy destruction increased as the cylinder inertia increased while the supply rate is constant. The second-law efficiency was the highest when cylinder inertia is the smallest. As compared to suction pressure and operating speed, cylinder inertia is the most practical and significant to be modified.

\section{Nomenclature}

$\dot{E}$ : Exergy supply rate (W)

$h$ : Specific enthalpy $\left(\mathrm{J} \cdot \mathrm{kg}^{-1}\right)$

$\dot{I}$ : Exergy destruction rate (W)

$\dot{m}$ : Mass flow rate $\left(\mathrm{kg} \cdot \mathrm{s}^{-1}\right)$

$\dot{Q}:$ Heat transfer rate $(\mathrm{W})$

$s:$ Specific entropy $\left(\mathrm{J} \cdot \mathrm{kg}^{-1}\right)$

$T$ : Temperature $(\mathrm{K})$

$\dot{w}$ : Power $(\mathrm{W})$.

\section{Greek Letters}

$\eta$ : Efficiency.

\section{Subscripts}

0: Ambient

$f$ : Friction

ht: Heat transfer

$i$ : Identifier for inlet flow stream

$j$ : Identifier for thermal mass

th: Throttling

$\mathrm{mx}$ : Mixing.

\section{Conflict of Interests}

The authors declare that there is no conflict of interests regarding the publication of this paper.

\section{Acknowledgment}

This work was financially supported in part by the Singapore National Research Foundation under its Campus for Research Excellence and Technological Enterprise (CREATE) programme.

\section{References}

[1] R. van Basshuysen and F. Schaefer, Internal Combustion Engine Handbook: Basics, Components, Systems and Perspectives, SAE International, Warrendale, Pa, USA, 2004.

[2] M. Sakita, "A cat-and-mouse type rotary engine: engine design and performance evaluation," Proceedings of the Institution of Mechanical Engineers D: Journal of Automobile Engineering, vol. 220, no. 8, pp. 1139-1151, 2006.

[3] Y.-T. Shen and Y.-R. Hwang, "Design and implementation of an air-powered motorcycles," Applied Energy, vol. 86, no. 7-8, pp. 1105-1110, 2009.

[4] Y. L. Teh and K. T. Ooi, "Design and friction analysis of the revolving vane compressor," in Proceedings of the International Compressor Engineering Conference at Purdue, C046, West Lafayette, Ind, USA, July 2006.

[5] Y. L. Teh and K. T. Ooi, "Theoretical study of a novel refrigeration compressor-part I: design of the revolving vane (RV) compressor and its frictional losses," International Journal of Refrigeration, vol. 32, no. 5, pp. 1092-1102, 2009.

[6] Y. L. Teh and K. T. Ooi, "Theoretical study of a novel refrigeration compressor-part III: leakage loss of the Revolving Vane (RV) compressor and a comparison with that of the rolling piston type," International Journal of Refrigeration, vol. 32, no. 5, pp. 945-952, 2009.

[7] A. Subiantoro and O. K. Tiow, "Introduction of the revolving vane expander," HVAC \& R Research, vol. 15, no. 4, pp. 801-816, 2009.

[8] A. Subiantoro and K. T. Ooi, "Design analysis of the novel revolving vane expander in a transcritical carbon dioxide refrigeration system," International Journal of Refrigeration, vol. 33, no. 4, pp. 675-685, 2010.

[9] A. Subiantoro and K. T. Ooi, "Comparison and performance analysis of the novel revolving vane expander design variants in low and medium pressure applications," Energy, vol. 78, pp. 747-757, 2014.

[10] International Transport Forum, Reducing Transport Greenhouse Gas Emissions-Trends \& Data. Transport and Innovation: Unleashing the Potential, International Transport Forum, 2010. 
[11] H. Chen, Y. Ding, Y. Li, X. Zhang, and C. Tan, "Air fuelled zero emission road transportation: a comparative study," Applied Energy, vol. 88, no. 1, pp. 337-342, 2011.

[12] B. R. Singh and O. Singh, "A study of performance output of a multivane air engine applying optimal injection and vane angles," International Journal of Rotating Machinery, vol. 2012, Article ID 578745, 10 pages, 2012.

[13] A. Subiantoro and K. T. Ooi, "Analytical study of the endface friction of the revolving vane mechanism," International Journal of Refrigeration, vol. 34, no. 5, pp. 1276-1285, 2011.

[14] J. A. McGovern, S. Harte, and G. Strikis, "Real gas performance analysis of a scroll or rotary compressor using exergy techniques," in Proceedings of the International Compressor Engineering Conference (ICEC '94), vol. 979, pp. 193-198, 1994.

[15] J. A. McGovern and S. Harte, "An exergy method for compressor performance analysis," International Journal of Refrigeration, vol. 18, no. 6, pp. 421-433, 1995.

[16] J. A. McGovern, "Exergy analysis-a different perspective on energy part 1: the concept of exergy," Proceedings of the Institution of Mechanical Engineers Part A: Journal of Power and Energy, vol. 204, no. 4, pp. 253-262, 1990.

[17] J. A. McGovern, "Exergy analysis-a different perspective on energy, part 2: rational efficiency and some examples of exergy analysis," Proceedings of the Institution of Mechanical Engineers, Part A: Journal of Power and Energy, vol. 204, no. 4, pp. 263-268, 1990.

[18] S. S. Stecco and G. Manfrida, "Exergy analysis of compression and expansion processes," Energy, vol. 11, no. 6, pp. 573-577, 1986.

[19] J. A. McGovern, "Compressor rational efficiencies," in Proceedings of the Institution of Mechanical Engineers, Developments in Industrial Compressors, vol. 10, pp. 59-67, 1989.

[20] A. V. Reddy, T. S. Kumar, D. K. T. Kumar, B. Dinesh, and Y. V. S. S. Santosh, "Energy and exergy analysis of I.C. engines," The International Journal of Engineering and Science, vol. 3, no. 5, pp. 7-26, 2014.

[21] M. Ameri, F. Kiaahmadi, M. Khanaki, and M. Nazoktabar, "Energy and exergy analyses of a spark-ignition engine," International Journal of Exergy, vol. 7, no. 5, pp. 547-563, 2010.

[22] C. Sayin, M. Hosoz, M. Canakci, and I. Kilicaslan, "Energy and exergy analyses of a gasoline engine," International Journal of Energy Research, vol. 31, no. 3, pp. 259-273, 2007.

[23] J. A. Caton, "Exergy destruction during the combustion process as functions of operating and design parameters for a sparkignition engine," International Journal of Energy Research, vol. 36, no. 3, pp. 368-384, 2012.

[24] S. Jafarmadar, R. Tasoujiazar, and B. Jalilpour, "Exergy analysis in a low heat rejection IDI diesel engine by three dimensional modeling," International Journal of Energy Research, vol. 38, no. 6, pp. 791-803, 2014.

[25] A. Subiantoro, K. S. Yap, and K. T. Ooi, "Experimental investigations of the revolving vane (RV-I) expander," Applied Thermal Engineering, vol. 50, no. 1, pp. 393-400, 2013.

[26] A. C. Yunus and M. A. Boles, Thermodynamics: An Engineering Approach, McGraw Hill, New York, NY, USA, 5th edition, 2016. 


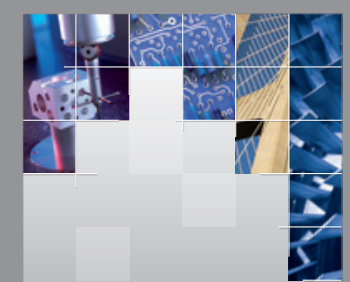

\section{Enfincering}
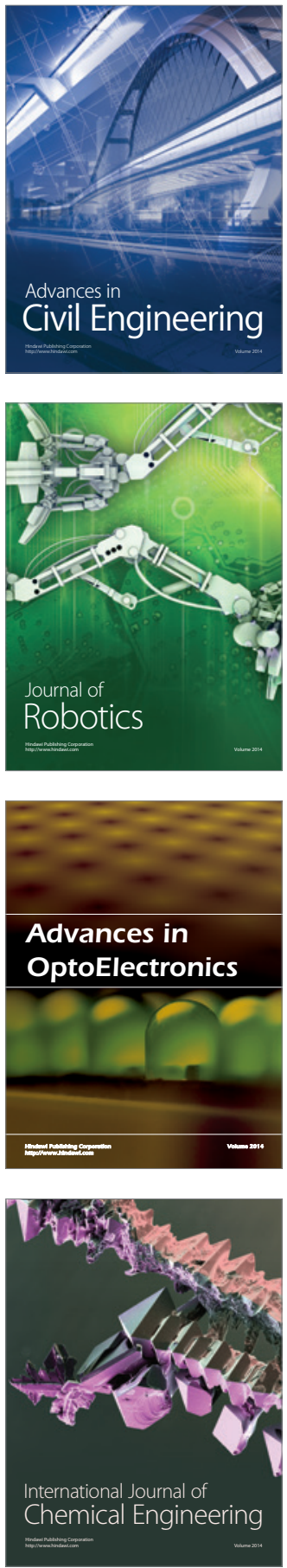

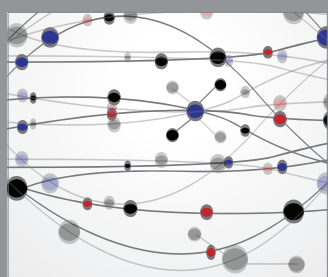

The Scientific World Journal

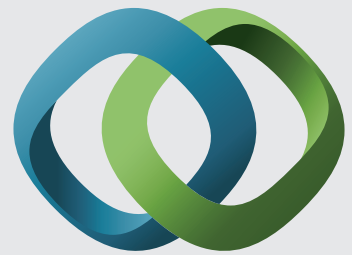

\section{Hindawi}

Submit your manuscripts at

http://www.hindawi.com
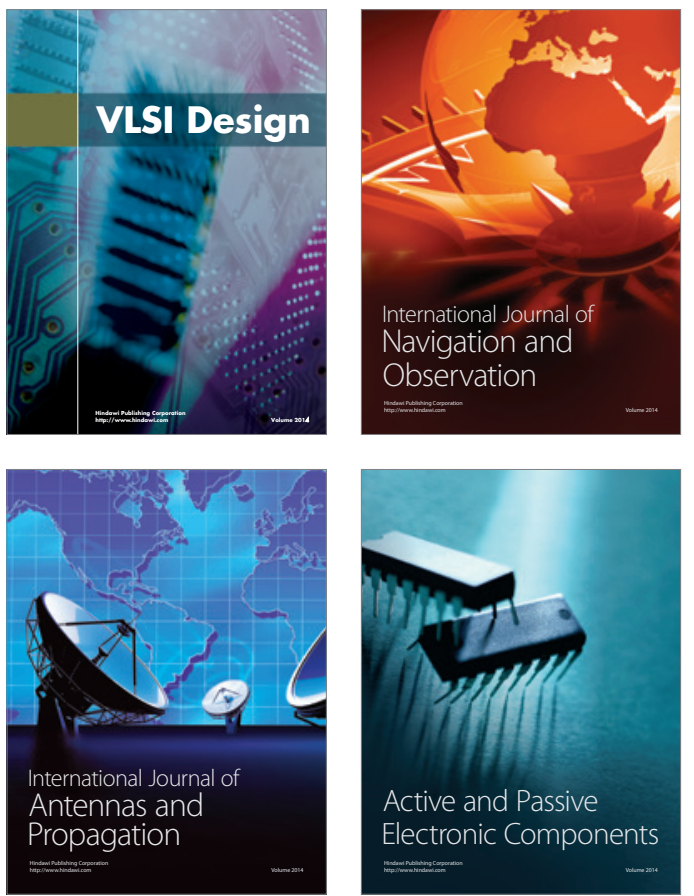
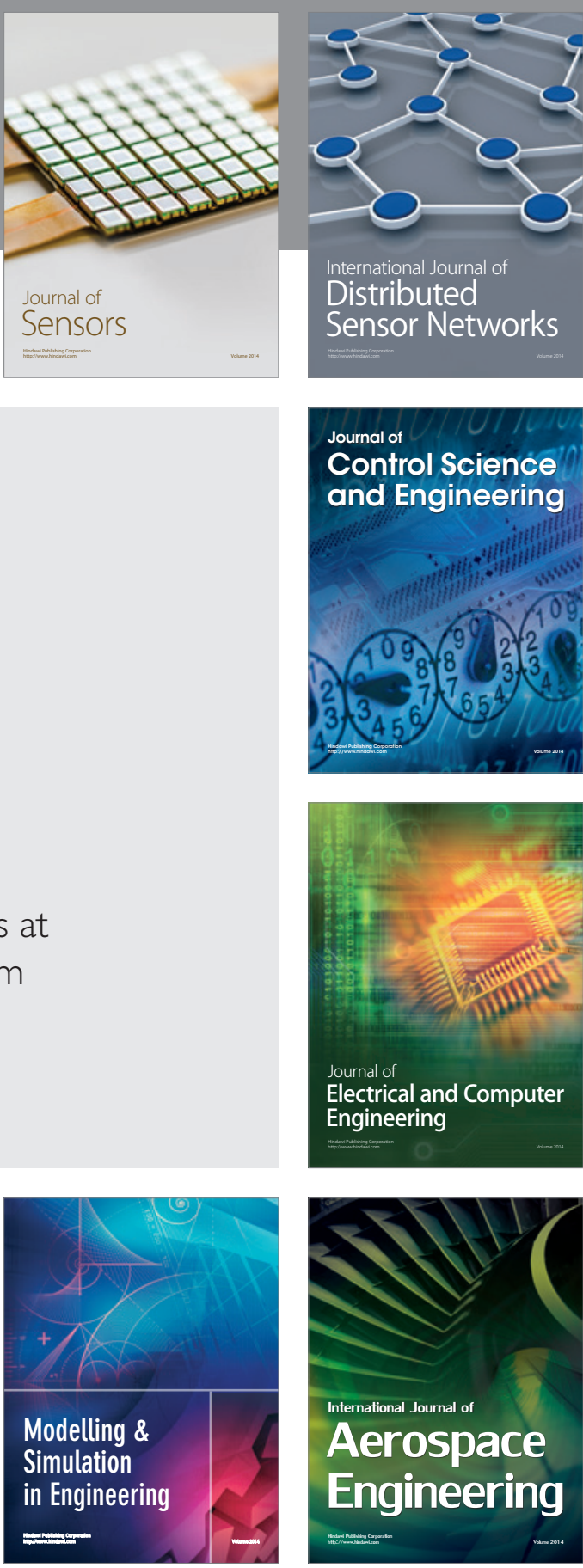

International Journal of

Distributed

Sensor Networks

Journal of

Control Science

and Engineering
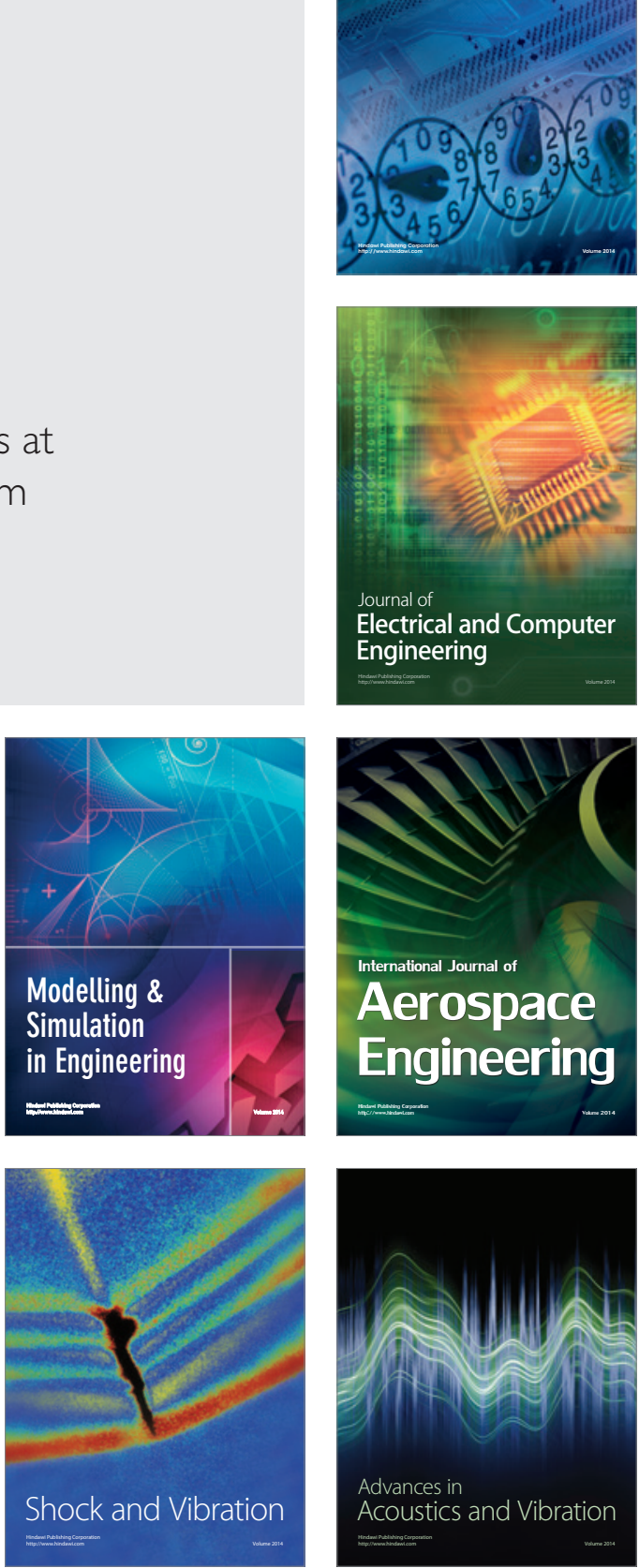